\title{
Article
}

\section{Association of Flow Rate of Prehospital Oxygen Administration and Clinical Outcomes in Severe Traumatic Brain Injury}

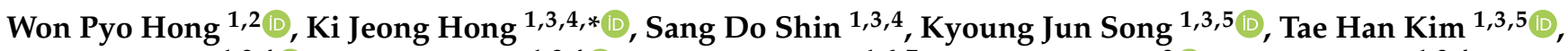 \\ Jeong Ho Park ${ }^{1,3,4} \mathbb{D}_{\text {, Young Sun Ro }}^{1,3,4} \mathbb{D}^{\text {, }}$, Seung Chul Lee ${ }^{1,6,7}$, Chu Hyun Kim ${ }^{8}\left(\mathbb{D}\right.$ and Joo Jeong ${ }^{1,3,4}$ \\ 1 Laboratory of Emergency Medical Services, Biomedical Research Institute, Seoul National University \\ Hospital, Seoul 03080, Korea; pyotang@gmail.com (W.P.H.); shinsangdo@gmail.com (S.D.S.); \\ skci-va@gmail.com (K.J.S.); adoong2001@gmail.com (T.H.K.); timthe@gmail.com (J.H.P.); \\ Ro.youngsun@gmail.com (Y.S.R.); scl0126@hanmail.net (S.C.L.); yukijeje@gmail.com (J.J.) \\ 2119 EMS Division, The Korean National Fire Agency, Sejong City 30128, Korea \\ 3 Department of Emergency Medicine, College of Medicine, Seoul National University, Seoul 03080, Korea \\ 4 Department of Emergency Medicine, Seoul National University Hospital, Seoul 03080, Korea \\ 5 Department of Emergency Medicine, Boramae Medical Center, Seoul Metropolitan Government-Seoul \\ National University, Seoul 07061, Korea \\ 6 Graduate School, Dongguk University, Goyang-si 10326, Korea \\ 7 Department of Emergency medicine, Emergency Medical Center, Dongguk University, Ilsan Hospital, \\ Goyang-si 10326, Korea \\ 8 Department of Emergency Medicine, Inje University College of Medicine, Seoul Paik Hospital, \\ Seoul 04551, Korea; juliannnn@hanmail.net \\ * Correspondence: emkjhong@gmail.com
}

check for updates

Citation: Hong, W.P.; Hong, K.J.; Shin, S.D.; Song, K.J.; Kim, T.H.; Park, J.H.; Ro, Y.S.; Lee, S.C.;

Kim, C.H.; Jeong, J. Association of Flow Rate of Prehospital Oxygen Administration and Clinical Outcomes in Severe Traumatic Brain Injury. J. Clin. Med. 2021, 10, 4097. https://doi.org/10.3390/jcm10184097

Academic Editor: Rafael Badenes

Received: 15 July 2021

Accepted: 8 September 2021

Published: 10 September 2021

Publisher's Note: MDPI stays neutral with regard to jurisdictional claims in published maps and institutional affiliations.

Copyright: (c) 2021 by the authors. Licensee MDPI, Basel, Switzerland. This article is an open access article distributed under the terms and conditions of the Creative Commons Attribution (CC BY) license (https:// creativecommons.org/licenses/by/ $4.0 /)$.
Abstract: The goal of this study was to investigate the association of prehospital oxygen administration flow with clinical outcome in severe traumatic brain injury (TBI) patients. This was a cross-sectional observational study using an emergency medical services-assessed severe trauma database in South Korea. The sample included adult patients with severe blunt TBI without hypoxia who were treated by EMS providers in 2013 and 2015. Main exposure was prehospital oxygen administration flow rate (no oxygen, low-flow 1 5, mid-flow 6 14, high-flow $15 \mathrm{~L} / \mathrm{min}$ ). Primary outcome was in-hospital mortality. A total of 1842 patients with severe TBI were included. The number of patients with no oxygen, low-flow oxygen, mid-flow oxygen, high-flow oxygen was $244,573,607$, and 418, respectively. Mortality of each group was $34.8 \%, 32.3 \%, 39.9 \%$, and $41.1 \%$, respectively. Compared with the no-oxygen group, adjusted odds (95\% CI) for mortality in the low-, mid-, and high-flow oxygen groups were $0.86(0.62-1.20), 1.15$ (0.83-1.60), and 1.21 (0.83-1.73), respectively. In the interaction analysis, low-flow oxygen showed lower mortality when prehospital saturation was 94-98\% (adjusted odds ratio (AOR): 0.80 (0.67-0.95)) and $\geq 99 \%$ (AOR: 0.69 (0.53-0.91)). Highflow oxygen showed higher mortality when prehospital oxygen saturation was $\geq 99 \%$ (AOR: 1.33 (1.01 1.74)). Prehospital low-flow oxygen administration was associated with lower in-hospital mortality compared with the no-oxygen group. High-flow administration showed higher mortality.

Keywords: traumatic brain injury; prehospital; oxygenation; hypoxia; hyperoxia; emergency medical services

\section{Introduction}

Traumatic brain injury (TBI) is a major health and socioeconomic problem throughout the world [1]. About 5.48 million people are estimated to suffer from severe TBI each year (73 cases per 100,000 people), and the economic and social impact of TBI is considerable due to the direct and indirect costs of treatment, rehabilitation, and permanent sequelae. The World Health Organization reported the TBI global incidence is rising and was predicted to surpass many diseases as a major cause of death and disability by the year $2020[2,3]$.

Prehospital hypoxia less than $90 \%$ of saturation was associated with higher mortality in previous studies, and Guidelines for the Management of Severe Traumatic Brain Injury 
recommends that hypoxia (partial pressure of oxygen in arterial blood $(\mathrm{PaO} 2)<60 \mathrm{mmHg}$ or peripheral oxygen saturation $(\mathrm{SpO} 2)<90 \%$ ) should be avoided, but there is no therapeutic range of oxygen saturation [4-6]. The Prehospital Trauma Life Support manual suggests that oxygen delivery should be provided based on the patient's breathing frequency, and this tends to encourage the use of a high fraction of inspired oxygen, which results in the common use of high-flow (15 L/min) oxygen administration [7].

However, recent studies, especially in intensive care unit settings, report that not only hypoxia but hyperoxia was associated with poor outcomes [8-11]. Oxidative stress with consequent impairment of endogenous antioxidant defense mechanisms plays a significant role in the secondary events leading to neuronal death [12].

Recent study of TBI management recommends an optimal PaO2 of more than $60 \mathrm{mmHg}$ and less than $200 \mathrm{mmHg}$ [13]. There are no guidelines on oxygen saturation level for optimal care in the prehospital setting, and possible effects of hyperoxia from high-flow oxygenation can easily be neglected. Prehospital high-flow oxygen administration is likely not associated with poor outcome because of short transportation time. It is uncertain, however, whether high-flow oxygen administration during emergency medical services (EMS) treatment is associated with poor outcomes from TBI.

The purpose of this study was to determine the association of prehospital oxygen administration flow rate on hospital mortality and neurological outcomes in severe TBI patients without hypoxia. We hypothesized that excessive oxygenation would adversely affect survival in patients with severe TBI without hypoxia.

\section{Materials and Methods}

\subsection{Study Design}

This was a cross-sectional observational study using a database from the nationwide registry of EMS-assessed severe trauma in Korea. This national severe trauma database was built from two data sources, including the EMS severe trauma registry recorded by EMS providers and hospital medical records collected by the Korea Disease Control and Prevention Agency. The study was reviewed and approved by the institutional review board of the study institution and informed consent was waived (Approval number: 1206-024-412).

\subsection{Study Setting}

The emergency medical services system in Korea is a single-tiered public service model by the government-run fire department. The service level of prehospital care is comparable with intermediate-level emergency medical technicians in the United States. Prehospital TBI protocol includes airway management and oxygen administration to the patient with hypoxia less than $94 \%$ of saturation $(\mathrm{SpO} 2<94 \%)$ to avoid hypoxia, but there is no clear flow rate or method of oxygen administration or target saturation level. According to capacity and resources, emergency departments in Korea are divided into levels 1 to 3 , and for the patients with severe trauma, and prehospital protocol recommends transferring patients with severe TBI to a level 1 or 2 emergency department for proper management.

\subsection{Data Source}

This study used the nationwide registry of the EMS-ST database built from the EMS severe trauma registry and hospital medical records. EMS providers used a field triage scheme consisting of four decision steps (physiologic, anatomic, mechanism of injury, and special considerations) to include patients with possible severe trauma [14], and the EMS severe trauma registry includes basic ambulance operation information and detailed prehospital monitoring and treatment information. Hospital medical records were collected by Korean CDC reviewers who received $26 \mathrm{~h}$ in an education course that included the coding for an abbreviated injury scale (AIS). The quality management committee, which consisted of emergency physicians, epidemiologists, statistical experts, and medical record review experts, held monthly meetings for quality assurance. 


\subsection{Selection of Participants}

The study population included all patients with severe TBI who were treated by EMS providers in 10 provinces between January and December 2013 and in 17 provinces (whole country) between January and December 2015. All patients with severe blunt TBI older than 15 years old were enrolled. Severe TBI was defined according to an AIS score of 3 or above for a head lesion. Patients who had cardiac arrest at the scene, unknown prehospital oxygen saturation, prehospital hypoxia less than $94 \%$ of oxygen saturation $(\mathrm{SpO} 2<94 \%)$, and unknown prehospital blood pressure or who had unknown information on hospital outcomes were excluded.

\subsection{Variables and Measurements}

The main exposure of interest was prehospital oxygen flow by EMS providers. Patients without oxygen administration were considered as reference, and low-flow oxygen was defined as $1 \sim 5 \mathrm{~L} / \mathrm{min}$ of oxygen administration, mid-flow oxygen as $6 \sim 14 \mathrm{~L} / \mathrm{min}$, and high-flow oxygen as $15 \mathrm{~L} / \mathrm{min}$, regardless of method of oxygen supply. High prehospital oxygen saturation status was defined as more than $99 \%$ of oxygen saturation (SpO2 $\geq 99 \%$ ) after oxygen administration.

Collected variables were demographic factors (age, gender, place of residence, past medical history), injury-related factors (time of trauma, place of injury, mechanism of injury (blunt or not)), prehospital factors (EMS transportation time, prehospital vital sign, and prehospital treatment, including amount of oxygen administration and prehospital oxygen saturation after oxygen administration), and hospital factors (level of emergency department, Injury Severity Score), as well as patient outcome after admission if the patient was admitted, and Glasgow Outcome Scale at hospital discharge.

\subsection{Outcome}

The primary outcome of the study was in-hospital mortality, defined as death in the emergency department or during admission, resulting from the injury. The secondary outcome was morbidity of patients, which was defined as poor according to the Glasgow Outcome Scale from 3 to 5 at hospital discharge.

\subsection{Statistical Analysis}

Descriptive analyses were performed to examine the distributions of the study variables. Counts and proportions were used for categorical variables, and medians and interquartile ranges were used for continuous variables. Categorical variables were assessed with the chi-square test, and continuous variables were compared using Mann-Whitney $U$ tests. The $p$-values were based on a two-sided significance level of 0.05 .

Adjusted odds ratios (AORs) with $95 \%$ confidence intervals (CIs) for saturation status for the study outcomes were calculated using multivariable logistic regression analysis, with no oxygen administration as the reference. The model was adjusted for gender, age, and underlying comorbidity; season and weekday; mechanism, intent, and alcohol; response time interval, scene time interval, and transport time interval; patient alertness, presence of hypotension (systolic blood pressure below $90 \mathrm{mmHg}$ in prehospital setting), and level of emergency department; and Injury Severity Score from 9 to 15, 16 to 24, and above 25 .

To determine the effect of hyperoxia on the patient, this study developed an interaction model with an interaction term between prehospital oxygen flow and prehospital saturation status as the final multivariable logistic model for the study outcomes. All statistical analysis was performed using SAS software, version 9.4 (SAS Institute Inc., Cary, NC, USA).

\section{Results}

A total of 35,169 patients were enrolled in the EMS-ST database during 2013 and 2015. The number of severe blunt traumatic brain injuries was 7697. After excluding ineligible patients, the final study population consisted of 1842 patients (Figure 1). Of the 1842 patients, 
the number of patients with no oxygen, low-flow oxygen, mid-flow oxygen, and highflow oxygen was $244(13.2 \%), 573(31.1 \%), 607(32.9 \%)$ and $418(22.7 \%)$, respectively; the in-hospital mortality rates were $34.8 \%, 32.3 \%, 39.9 \%$ and $41.1 \%$, respectively. Basic patient demographics are shown in Table 1. Patients were older in the no-oxygen group (median age was 61 years old) compared with other groups (median age 46, 44, and 37, respectively). Patient's residence, mechanism of injury, patient's alertness, prehospital hypotension, prehospital advanced airway management, prehospital IV access, and prehospital transport time were associated with the flow rate of oxygen administration (Tables 1 and 2).

In the multivariable logistic regression analysis, low-flow oxygen administration was likely to have better in-hospital outcomes (AOR $0.86(0.62-1.20)$ for in-hospital mortality and AOR 0.80 (0.57-1.10) for poor neurologic outcome) (Table 3.) High-flow oxygen administration was likely to have more mortality and poor neurologic outcome compared with the no-oxygen administration group (AOR 1.21 (0.83-1.73) for mortality and $1.15(0.81-1.64)$ for poor neurological outcome).

In the interaction model, using prehospital oxygenation and prehospital saturation status, the low-flow oxygen group showed low in-hospital mortality and better neurologic outcome in both saturation groups. Adjusted odds ratio (AOR) $(95 \% \mathrm{CI})$ for mortality was $0.80(0.67-0.95)$ in the $94 \sim 98 \%$ group and 0.69 (0.53-0.91) in 99 100\% group. High-flow oxygen administration showed poor in hospital outcome (AOR (95\% CI) was 1.33 (1.01-1.74)) in patients with high prehospital saturation (SpO2 $\geq 99 \%$ ), which was statistically significant $(p=0.04)$ (Table 4$)$.

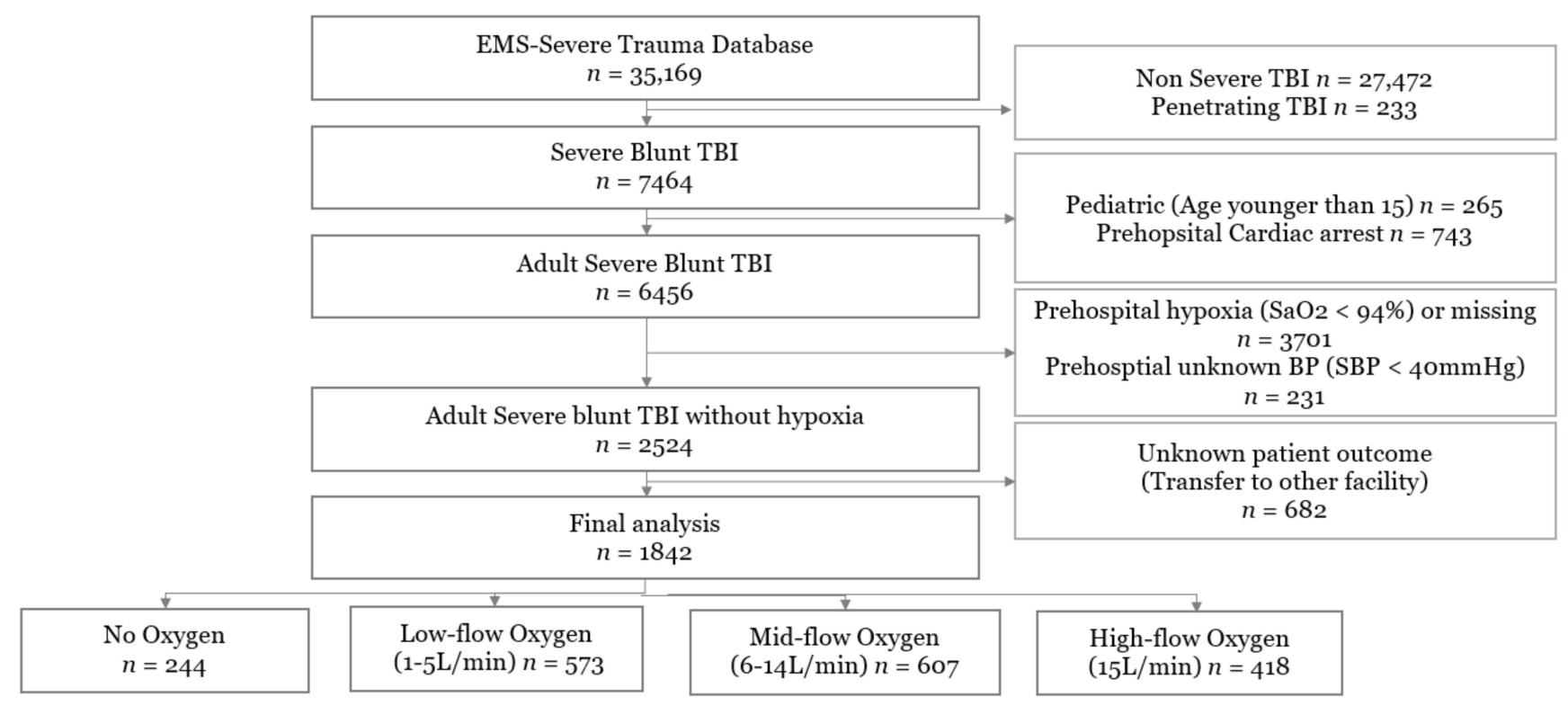

Figure 1. Inclusion of study population.

Table 1. Demographics of the study population.

\begin{tabular}{|c|c|c|c|c|c|c|c|c|c|c|c|}
\hline & \multirow{2}{*}{\multicolumn{2}{|c|}{ Total }} & \multirow{2}{*}{\multicolumn{2}{|c|}{ No Oxygen }} & \multicolumn{6}{|c|}{ Flow Rate of Oxygen Administration } & \multirow{3}{*}{$p$-Value } \\
\hline & & & & & \multicolumn{2}{|c|}{ Low } & \multicolumn{2}{|c|}{ Mid } & \multicolumn{2}{|c|}{ High } & \\
\hline & $n$ & $\%$ & $n$ & $\%$ & $n$ & $\%$ & $n$ & $\%$ & $n$ & $\%$ & \\
\hline Total & 1842 & 100 & 244 & 100 & 573 & 100 & 607 & 100 & 418 & 100 & \multirow{4}{*}{0.16} \\
\hline Gender & & & & & & & & & & & \\
\hline Male & 1370 & 74.4 & 169 & 69.3 & 438 & 76.4 & 457 & 75.3 & 306 & 73.2 & \\
\hline Female & 472 & 25.6 & 75 & 30.7 & 135 & 23.6 & 150 & 24.7 & 112 & 26.8 & \\
\hline \multicolumn{5}{|l|}{ Age, years } & & & & & & & \multirow[t]{4}{*}{$<0.01$} \\
\hline $15-64$ & 1123 & 61.0 & 141 & 57.8 & 317 & 55.3 & 373 & 61.4 & 292 & 69.9 & \\
\hline $65-$ & 719 & 39.0 & 103 & 42.2 & 256 & 44.7 & 234 & 38.6 & 126 & 30.1 & \\
\hline Median (IQR) & \multicolumn{2}{|c|}{$58(45-71)$} & \multicolumn{2}{|c|}{$61(51-72)$} & \multicolumn{2}{|c|}{$46(60-74)$} & \multicolumn{2}{|c|}{$44(57-70)$} & \multicolumn{2}{|c|}{$37(54-67)$} & \\
\hline
\end{tabular}


Table 1. Cont.

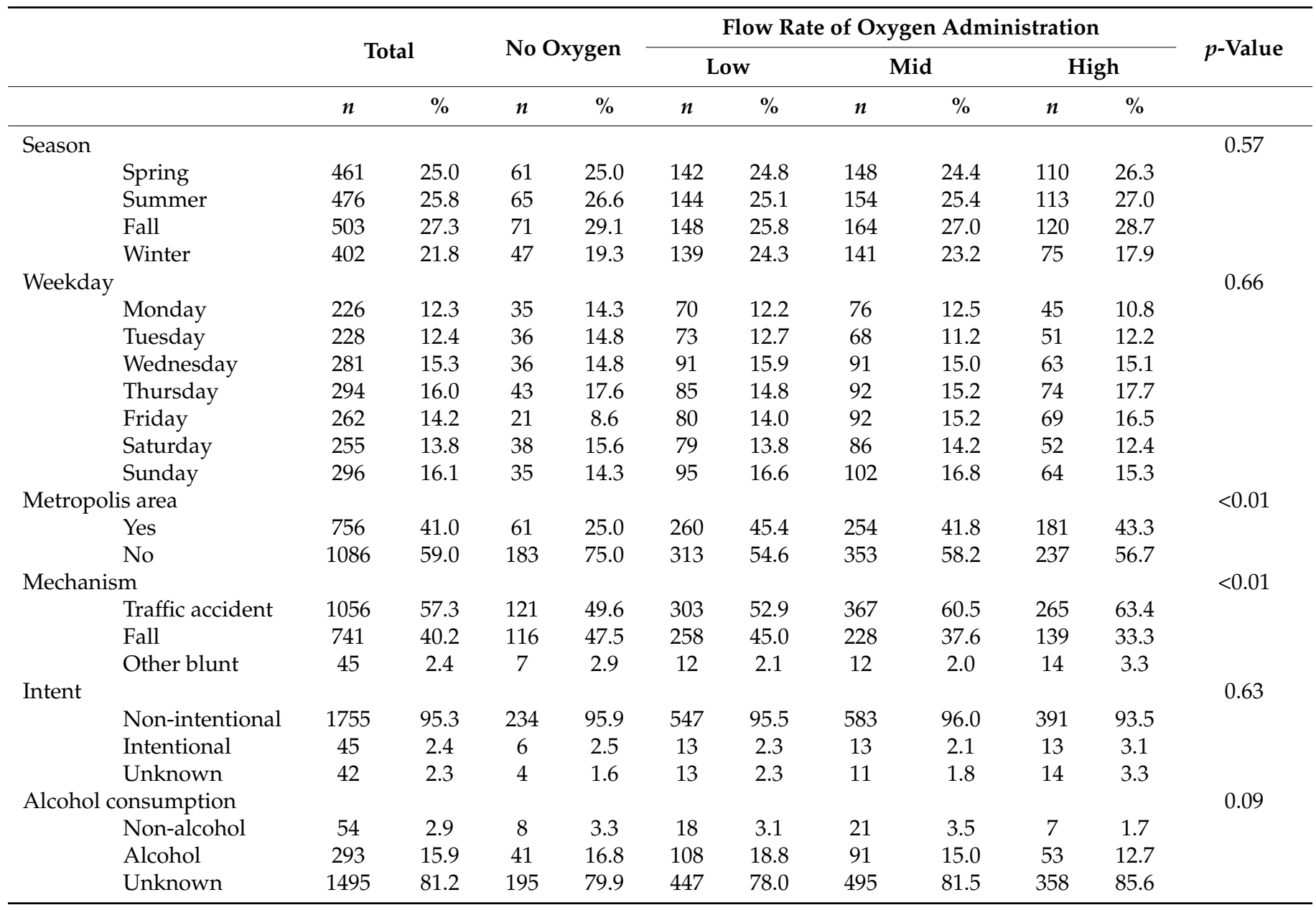

Table 2. Pre-hospital and in-hospital clinical findings according to flow rate of oxygen administration.

\begin{tabular}{|c|c|c|c|c|c|c|c|c|c|c|c|}
\hline & \multirow{2}{*}{\multicolumn{2}{|c|}{ Total }} & \multirow{2}{*}{\multicolumn{2}{|c|}{ No Oxygen }} & \multicolumn{6}{|c|}{ Flow Rate of Oxygen Administration } & \multirow{3}{*}{$p$-Value } \\
\hline & & & & & \multicolumn{2}{|c|}{ Low } & \multicolumn{2}{|c|}{ Mid } & \multicolumn{2}{|c|}{ High } & \\
\hline & $n$ & $\%$ & $n$ & $\%$ & $n$ & $\%$ & $n$ & $\%$ & $n$ & $\%$ & \\
\hline Total & 1842 & 100 & 244 & 100 & 573 & 100 & 607 & 100.0 & 418 & 100 & \\
\hline Patient alertness & & & & & & & & & & & $<0.01$ \\
\hline Alert & 284 & 15.4 & 65 & 26.6 & 122 & 21.3 & 64 & 10.5 & 33 & 7.9 & \\
\hline Verbal & 416 & 22.6 & 88 & 36.1 & 155 & 27.1 & 122 & 20.1 & 51 & 12.2 & \\
\hline Pain & 792 & 43.0 & 75 & 30.7 & 235 & 41.0 & 281 & 46.3 & 201 & 48.1 & \\
\hline Unresponsive & 350 & 19.0 & 16 & 6.6 & 61 & 10.6 & 140 & 23.1 & 133 & 31.8 & \\
\hline Prehospital SBP & & & & & & & & & & & $<0.01$ \\
\hline$<90 \mathrm{mmHg}$ & 110 & 6.0 & 6 & 2.5 & 23 & 4.0 & 41 & 6.8 & 40 & 9.6 & \\
\hline$\geq 90 \mathrm{mmHg}$ & 1732 & 94.0 & 238 & 97.5 & 550 & 96.0 & 566 & 93.2 & 378 & 90.4 & \\
\hline Prehospital Saturation & & & & & & & & & & & 0.07 \\
\hline $94-98 \%$ & 1054 & 57.2 & 132 & 54.1 & 354 & 61.8 & 336 & 55.4 & 232 & 55.5 & \\
\hline $99-100 \%$ & 788 & 42.8 & 112 & 45.9 & 219 & 38.2 & 271 & 44.6 & 186 & 44.5 & \\
\hline Prehospital advance airway & & & & & & & & & & & $<0.01$ \\
\hline No & 1816 & 98.6 & 243 & 99.6 & 572 & 99.8 & 598 & 98.5 & 403 & 96.4 & \\
\hline Yes & 26 & 1.4 & 1 & 0.4 & 1 & 0.2 & 9 & 1.5 & 15 & 3.6 & \\
\hline
\end{tabular}


Table 2. Cont.

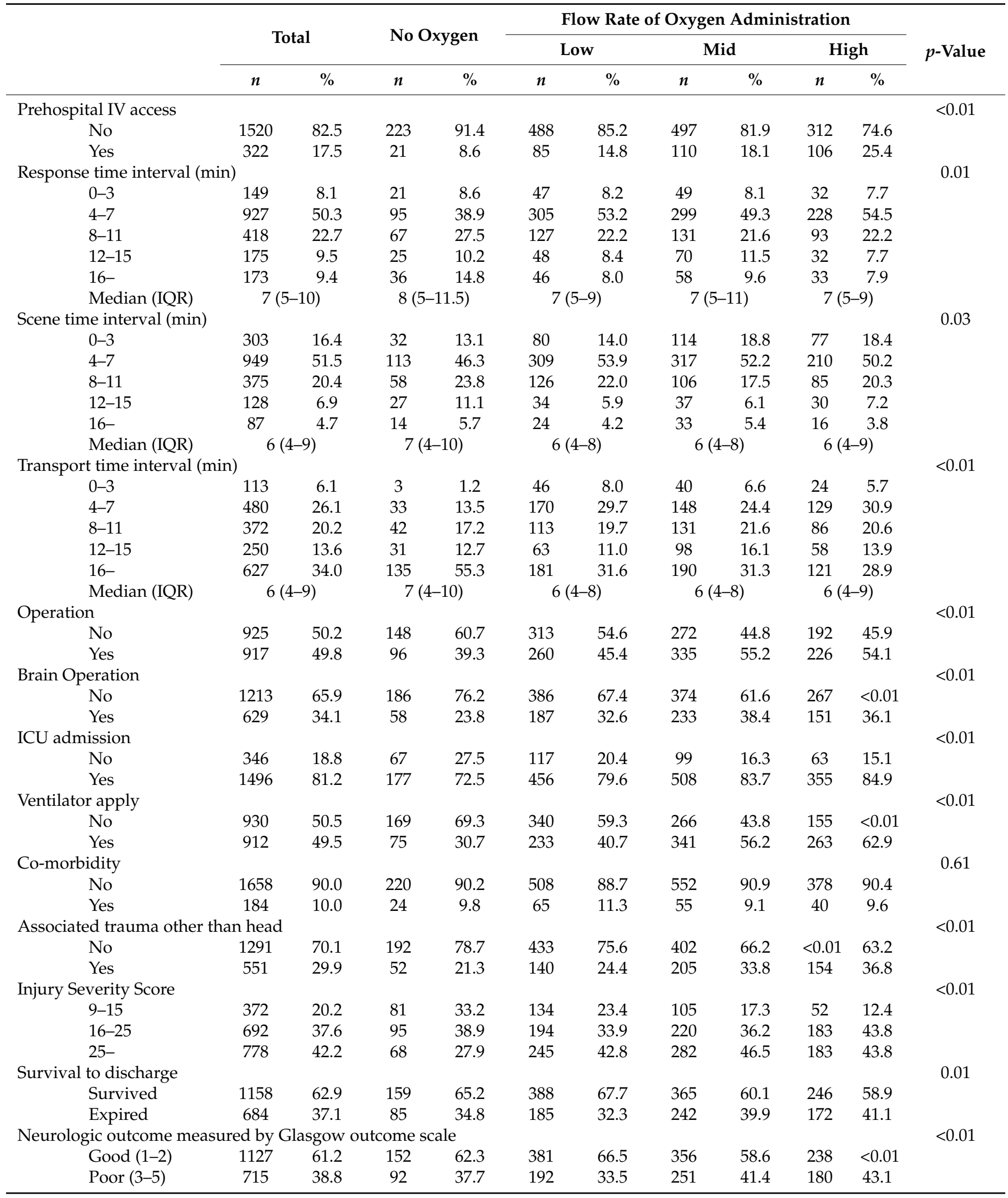


Table 3. Pre-hospital and in-hospital clinical findings according to flow rate of oxygen administration.

\begin{tabular}{|c|c|c|c|c|c|c|}
\hline & \multirow{2}{*}{$\begin{array}{c}\text { Total } \\
n\end{array}$} & \multicolumn{2}{|c|}{ Outcome } & \multirow{2}{*}{$\begin{array}{c}\text { Unadjusted } \\
\text { OR }(95 \% \mathrm{CI})\end{array}$} & \multirow{2}{*}{$\begin{array}{c}\text { Adjusted Model } 1 \text { * } \\
\text { OR }(95 \% \text { CI })\end{array}$} & \multirow{2}{*}{$\begin{array}{c}\text { Adjusted Model } 2 * * \\
\text { OR }(95 \% \text { CI })\end{array}$} \\
\hline & & $n$ & $\%$ & & & \\
\hline \multicolumn{7}{|c|}{ Primary outcome: in-hospital mortality } \\
\hline Total & 1842 & 684 & 37.1 & & & \\
\hline \multicolumn{7}{|l|}{ Oxygen flow rate $(\mathrm{L} / \mathrm{min})$} \\
\hline No oxygen & 244 & 85 & 34.8 & 1.00 & 1.00 & 1.00 \\
\hline Low-flow rate & 573 & 185 & 32.3 & $0.89(0.65-1.22)$ & $0.88(0.64-1.21)$ & $0.86(0.62-1.20)$ \\
\hline Mid-flow rate & 607 & 242 & 39.9 & $1.24(0.91-1.69)$ & $1.25(0.92-1.70)$ & $1.15(0.83-1.60)$ \\
\hline High-flow rate & 418 & 172 & 41.1 & $1.31(0.94-1.82)$ & $1.33(0.96-1.86)$ & $1.21(0.83-1.73)$ \\
\hline \multicolumn{7}{|c|}{ Secondary outcome: poor neurologic outcome } \\
\hline Total & 1842 & 715 & 38.8 & & & \\
\hline \multicolumn{7}{|l|}{ Oxygen flow rate $(\mathrm{L} / \mathrm{min})$} \\
\hline No oxygen & 244 & 92 & 37.7 & 1.00 & 1.00 & 1.00 \\
\hline Low-flow rate & 573 & 192 & 33.5 & $0.83(0.61-1.14)$ & $0.82(0.60-1.13)$ & $0.80(0.57-1.10)$ \\
\hline Mid-flow rate & 607 & 251 & 41.4 & $1.17(0.86-1.58)$ & $1.17(0.86-1.59)$ & $1.09(0.78-1.50)$ \\
\hline High-flow rate & 418 & 180 & 43.1 & $1.25(0.90-1.73)$ & $1.27(0.92-1.76)$ & $1.15(0.81-1.64)$ \\
\hline
\end{tabular}

* Model 1: Adjusted by gender, age, underlying co-morbidity; ** Model 2: Adjusted by gender, age, underlying co-morbidity, season, weekday, mechanism, intent, alcohol, response time interval, scene time interval, transport time interval, patient alertness, low blood pressure, abnormal respiration rate, intravenous fluid, prehospital oxygen saturation status or oxygen flow.

Table 4. Interaction analysis for clinical outcome according to oxygen flow rate by initial prehospital oxygen saturation level.

\begin{tabular}{|c|c|c|c|c|c|}
\hline & & \multirow{2}{*}{$\begin{array}{c}\text { Total } \\
n\end{array}$} & \multicolumn{2}{|c|}{ Outcome } & \multirow{2}{*}{$\begin{array}{l}\text { Adjusted OR * } \\
\text { OR } *(95 \% \mathrm{CI})\end{array}$} \\
\hline & & & $n$ & $\%$ & \\
\hline \multicolumn{6}{|c|}{ Primary outcome: in-hospital mortality } \\
\hline \multicolumn{6}{|c|}{ Saturation $94-98 \%$} \\
\hline & No oxygen administration & 132 & 48 & 36.4 & 1.00 \\
\hline & Low-flow rate $(1-5 \mathrm{~L} / \mathrm{min})$ & 354 & 127 & 35.9 & $0.80(0.67-0.95)$ \\
\hline & Mid-flow rate $(6-14 \mathrm{~L} / \mathrm{min})$ & 336 & 143 & 42.6 & $1.10(0.94-1.29)$ \\
\hline & High-flow rate $(15 \mathrm{~L} / \mathrm{min})$ & 232 & 96 & 41.4 & $1.18(0.98-1.42)$ \\
\hline \multicolumn{6}{|c|}{ Saturation $99-100 \%$} \\
\hline & No oxygen administration & 112 & 37 & 33.0 & 1.00 \\
\hline & Low-flow rate $(1-5 \mathrm{~L} / \mathrm{min})$ & 219 & 58 & 26.5 & $0.69(0.53-0.91)$ \\
\hline & Mid-flow rate $(6-14 \mathrm{~L} / \mathrm{min})$ & 271 & 99 & 36.5 & $1.05(0.83-1.34)$ \\
\hline & High-flow rate $(15 \mathrm{~L} / \mathrm{min})$ & 186 & 76 & 40.9 & $1.33(1.01-1.74)$ \\
\hline \multirow{2}{*}{\multicolumn{6}{|c|}{$\begin{array}{l}\text { Secondary outcome: poor neurologic outcome } \\
\text { Saturation } 94-98 \%\end{array}$}} \\
\hline & & & & & \\
\hline & No oxygen administration & 132 & 52 & 40.2 & 1.00 \\
\hline & Low-flow rate $(1-5 \mathrm{~L} / \mathrm{min})$ & 354 & 132 & 37.3 & $0.78(0.66-0.92)$ \\
\hline & Mid-flow rate $(6-14 \mathrm{~L} / \mathrm{min})$ & 336 & 149 & 44.3 & $1.09(0.93-1.27)$ \\
\hline & High-flow rate $(15 \mathrm{~L} / \mathrm{min})$ & 232 & 103 & 44.4 & $1.17(0.97-1.41)$ \\
\hline \multicolumn{6}{|l|}{ Saturation $99-100 \%$} \\
\hline & No oxygen administration & 112 & 39 & 34.8 & 1.00 \\
\hline & Low-flow rate $(1-5 \mathrm{~L} / \mathrm{min})$ & 219 & 60 & 27.4 & $0.69(0.53-0.91)$ \\
\hline & Mid-flow rate $(6-14 \mathrm{~L} / \mathrm{min})$ & 271 & 102 & 37.6 & $1.05(0.83-1.34)$ \\
\hline & High-flow rate $(15 \mathrm{~L} / \mathrm{min})$ & 186 & 77 & 41.4 & $1.29(0.98-1.69)$ \\
\hline
\end{tabular}

* Adjusted by gender, age, underlying co-morbidity, season, weekday, mechanism, intent, alcohol, response time interval, scene time interval, transport time interval, patient alertness, low blood pressure, abnormal respiration rate, intravenous fluid, prehospital oxygen saturation status or oxygen flow.

\section{Discussion}

Prehospital administration of oxygen is widespread in our practice, but resuscitative oxygen administration frequently exceeds the physiological needs of patients with TBI and without TBI $[7,15,16]$. Although this is usually accepted to avoid hypoxia, toxicity of oxygen to the brain and other vital organs due to reactive oxygen species is well described [17-20], and $100 \%$ oxygen can cause cerebral vasoconstriction, reducing cerebral perfusion $[21,22]$. 
In our study, the low-flow oxygen group showed low in-hospital mortality and better neurologic outcome. AOR $(95 \% \mathrm{CI})$ for mortality was $0.80(0.67-0.95)$ in the $94 \sim 98 \%$ group and $0.69(0.53-0.91)$ in the 99 100\% group in the interaction model. This result implies that low-flow $(1 \sim 5 \mathrm{~L} / \mathrm{min})$ oxygen administration could be helpful for the patients with severe TBI. Recent studies have reported that oxygen administration improves cerebral metabolism and decreases intracerebral pressure [23,24], and they recommend providing normo-baric hyperoxia in the treatment of patients with TBI, but other studies have reported contrary results [6], which needs further well-controlled study.

On the other hand, 186 patients $(10.1 \%)$ received high-flow oxygen, even though their prehospital saturation was above $99 \%$; mortality among them was highest $(40.9 \%)$ among all groups. Brenner et al. reported that hyperoxia, which was defined as $\mathrm{PaO} 2$ higher than $200 \mathrm{mmHg}$, within the first $24 \mathrm{~h}$ of hospitalization is associated with worse short-term functional outcomes and higher mortality after TBI [13], but other studies showed no significant difference in in-hospital mortality among patients with hyperoxia $(\mathrm{PaO} 2>300 \mathrm{mmHg}$ ) [25], and there was no association between maximum $\mathrm{PaO} 2$ in the first $24 \mathrm{~h}$ after admission and in-hospital mortality [26]. This study could not measure $\mathrm{PaO} 2$ due to the lack of a modality to measure it exactly in prehospital settings. Additionally, the hypothesis of this investigation was that a patient could have hyperoxia when oxygen saturation was above $99 \%$ after the administration of high-flow oxygen. In the interaction analysis, patients with high oxygen saturation after high-flow oxygen showed significantly poor outcomes (AOR 1.33 (95\%CI: 1.01-1.74)), which implies that hyperoxia could be harmful.

Some authors reported that prehospital advanced airway techniques were related to poor outcomes in traumatic brain injury and that this was associated with prehospital hyperventilation, which was very common $(60 \sim 70 \%)$; even the prehospital guideline recommends not to hyperventilate [27-30]. In this study setting, prehospital advanced airway techniques, including laryngeal mask airway and endotracheal intubation, were uncommon (1.4\%) because cases with prehospital hypoxia less than $94 \%$ were excluded. When we analyzed that separately, it did not influence our result.

The primary goal of treatment for patients with TBI is to prevent secondary brain injury. This includes providing adequate oxygenation and circulation to perfuse the brain. Oxygen should be titrated not only to prevent hypoxia but also to prevent hyperoxia. Lowflow oxygen administration could be helpful to patients with severe TBI, and indiscriminate high-flow oxygen administration could be harmful to patients with severe TBI. A more specific prehospital oxygen administration guideline (therapeutic target range of oxygen saturation $94-98 \%$ and restriction of indiscriminate high-flow oxygen) should be applied. Moreover, further study, such as a randomized controlled study, should be conducted to elucidate a clear causal relationship.

\section{Limitations}

First, this was a cross-sectional observational study using a database from the nationwide registry of EMS-assessed severe trauma in Korea. Patients with severe TBI who visited the emergency department in their own vehicle could have been omitted from this registry. Second, the definition of hypoxia used in this study was the cutoff value of SpO2 94\%, measured by pulse oximetry. The definition of hypoxia differed between the studies. Third, initiation time and duration of prehospital oxygen administration was not collected. Forth, additional physiologic parameters associated with outcome in TBI patients, such as $\mathrm{PaO} 2$, intracranial pressure, cerebral perfusion pressure, oxygen radicals, and cerebral metabolites, were not collected.

\section{Conclusions}

Prehospital low-flow oxygen administration was associated with low in-hospital mortality compared with the no-oxygen group in patients with severe traumatic brain injury, and high-flow oxygen administration showed higher mortality and could be harmful 
to patients with severe blunt traumatic brain injury. The proper therapeutic window for prehospital oxygenation may reduce the mortality rate of patients with severe TBI.

Author Contributions: Conceptualization, S.D.S. and K.J.S.; methodology, Y.S.R., T.H.K. and C.H.K.; software, W.P.H.; validation, Y.S.R., T.H.K. and C.H.K.; formal analysis, Y.S.R., T.H.K. and C.H.K.; investigation, W.P.H.; resources, J.H.P., J.J. and S.C.L.; data curation, J.H.P., J.J. and S.C.L.; writingoriginal draft preparation, W.P.H.; writing—review and editing, K.J.H.; visualization, W.P.H.; supervision, K.J.H.; project administration, K.J.H.; funding acquisition, none. All authors have read and agreed to the published version of the manuscript.

Funding: This research received no external funding.

Institutional Review Board Statement: The study was reviewed and approved by the institutional review board of the study institution (Approval number: 1206-024-412).

Informed Consent Statement: Patient consent was waived due to data collection from retrospective medical record review.

Data Availability Statement: Data was obtained from the Korea Disease Control and Prevention Agency and is available from the Korea Disease Control and Prevention Agency with the permission.

Acknowledgments: This study used the emergency medical services-based severe trauma database of the Korea Disease Control and Prevention Agency. Additionally, the use of the database for this study was approved by the Korea Disease Control and Prevention Agency.

Conflicts of Interest: The authors declare no conflict of interest.

\section{References}

1. Hyder, A.A.; Wunderlich, C.A.; Puvanachandra, P.; Gururaj, G.; Kobusingye, O.C. The impact of traumatic brain injuries: A global perspective. NeuroRehabilitation 2007, 22, 341-353. [CrossRef]

2. Iaccarino, C.; Carretta, A.; Nicolosi, F.; Morselli, C. Epidemiology of severe traumatic brain injury. J. Neurosurg. Sci. 2018, 62, 535-541. [CrossRef] [PubMed]

3. Kamal, V.K.; Agrawal, D.; Pandey, R.M. Epidemiology, clinical characteristics and outcomes of traumatic brain injury: Evidences from integrated level 1 trauma center in India. J. Neurosci. Rural Pract. 2016, 7, 515-525. [CrossRef]

4. Head Injury: Triage, Assessment, Investigation and Early Management of Head Injury in Infants, Children and Adults; NICE Guidance; NICE: London, UK, 2007.

5. Brain Trauma Foundation; American Association of Neurological Surgeons; Congress of Neurological Surgeons; Joint Section on Neurotrauma and Critical Care; AANS/CNS; Susan, L.B.; Randall, M.C.; Jamshid, G.; Flora, F.M.H.; Odette, A.H.; et al. Guidelines for the management of severe traumatic brain injury. I. Blood pressure and oxygenation. J. Neurotrauma 2007, 24, S7-S13.

6. Spaite, D.W.; Hu, C.; Bobrow, B.J.; Chikani, V.; Barnhart, B.; Gaither, J.B.; Denninghoff, K.R.; Anderson, P.D.; Keim, S.M.; Viscusi, C.; et al. The Effect of Combined Out-of-Hospital Hypotension and Hypoxia on Mortality in Major Traumatic Brain Injury. Ann. Emerg. Med. 2017, 69, 62-72. [CrossRef] [PubMed]

7. Wolfl, C.G.; Bouillon, B.; Lackner, C.K.; Wentzensen, A.; Gliwitzky, B.; Gross, B.; Brokmann, J.; Hauer, T. Prehospital Trauma Life Support (PHTLS): An interdisciplinary training in preclinical trauma care. Unfallchirurg 2008, 111, 688-694. [CrossRef] [PubMed]

8. Stolmeijer, R.; Bouma, H.R.; Zijlstra, J.G.; Drost-de Klerck, A.M.; Ter Maaten, J.C.; Ligtenberg, J.J.M. A Systematic Review of the Effects of Hyperoxia in Acutely Ill Patients: Should We Aim for Less? BioMed Res. Int. 2018, 14, 7841295. [CrossRef]

9. Taher, A.; Pilehvari, Z.; Poorolajal, J.; Aghajanloo, M. Effects of Normobaric Hyperoxia in Traumatic Brain Injury: A Randomized Controlled Clinical Trial. Trauma Mon. 2016, 21, e26772. [CrossRef] [PubMed]

10. Damiani, E.; Donati, A.; Girardis, M. Oxygen in the critically ill: Friend or foe? Curr. Opin. Anaesthesiol. 2018, 31, 129-135. [CrossRef]

11. Rincon, F.; Kang, J.; Vibbert, M.; Urtecho, J.; Athar, M.K.; Jallo, J. Significance of arterial hyperoxia and relationship with case fatality in traumatic brain injury: A multicentre cohort study. J. Neurol. Neurosurg. Psychiatry 2014, 85, 799-805. [CrossRef]

12. Frati, A.; Cerretani, D.; Fiaschi, A.I.; Frati, P.; Gatto, V.; Russa, R.L.; Pesce, A.; Pinchi, E.; Santurro, A.; Fraschetti, F.; et al. Diffuse Axonal Injury and Oxidative Stress: A Comprehensive Review. Int. J. Mol. Sci. 2017, 18, 2600. [CrossRef]

13. Brenner, M.; Stein, D.; Hu, P.; Kufera, J.; Wooford, M.; Scalea, T. Association between early hyperoxia and worse outcomes after traumatic brain injury. Arch Surg. 2012, 147, 1042-1046. [CrossRef]

14. Sasser, S.M.; Hunt, R.C.; Sullivent, E.E.; Wald, M.M.; Mitchko, J.; Jurkovich, G.J.; Henry, M.C.; Salomone, J.P.; Wang, S.C.; Galli, R.L.; et al. National Expert Panel on Field Triage, Centers for Disease Control and Prevention (CDC). Guidelines for field triage of injured patients. Recommendations of the National Expert Panel on Field Triage. MMWR Recomm. Rep. 2009, $58,1-35$.

15. Hopple, J. No clue about $\mathrm{O}(2)$ : Teaching oxygen therapy to prehospital providers. JEMS 2011, 36, 26-29. [PubMed] 
16. Cornet, A.D.; Kooter, A.J.; Peters, M.J.; Smulders, Y.M. Supplemental oxygen therapy in medical emergencies: More harm than benefit? Arch Intern. Med. 2012, 172, 289-290. [CrossRef]

17. Bostek, C.C. Oxygen toxicity: An introduction. AANA J. 1989, 57, 231-237.

18. Demchenko, I.T.; Welty-Wolf, K.E.; Allen, B.W.; Piantadosi, C.A. Similar but not the same: Normobaric and hyperbaric pulmonary oxygen toxicity, the role of nitric oxide. Am. J. Physiol.- Lung Cell. Mol. Physiol. 2007, 293, 229-238. [CrossRef] [PubMed]

19. Bitterman, N. CNS oxygen toxicity. Undersea Hyperb. Med. 2004, 31, 63-72.

20. Doppenberg, E.M.; Rice, M.R.; Di, X.; Young, H.F.; Woodward, J.J.; Bullock, R. Increased free radical production due to subdural hematoma in the rat: Effect of increased inspired oxygen fraction. J. Neurotrauma 1998, 15, 337-347. [CrossRef] [PubMed]

21. Rossi, S.; Stocchetti, N.; Longhi, L.; Balestreri, M.; Spagnoli, D.; Zanier, E.R.; Bellinzona, G. Brain oxygen tension, oxygen supply, and oxygen consumption during arterial hyperoxia in a model of progressive cerebral ischemia. J. Neurotrauma 2001, 18, 163-174. [CrossRef]

22. Bulte, D.P.; Chiarelli, P.A.; Wise, R.G.; Jezzard, P. Cerebral perfusion response to hyperoxia. J. Cereb. Blood Flow Metab. 2007, 27, 69-75. [CrossRef]

23. Tolias, C.M.; Reinert, M.; Seiler, R.; Gilman, C.; Scharf, A.; Bullock, M.R. Normobaric hyperoxia-induced improvement in cerebral metabolism and reduction in intracranial pressure in patients with severe head injury: A prospective historical cohort-matched study. J. Neurosurg. 2004, 101, 435-444. [CrossRef]

24. Diringer, M.N.; Aiyagari, V.; Zazulia, A.R.; Videen, T.O.; Powers, W.J. Effect of hyperoxia on cerebral metabolic rate for oxygen measured using positron emission tomography in patients with acute severe head injury. J. Neurosurg. 2007, 106, 526-529. [CrossRef] [PubMed]

25. Briain, D.Ó.; Nickson, C.; Pilcher, D.V.; Udy, A.A. Early Hyperoxia in Patients with Traumatic Brain Injury Admitted to Intensive Care in Australia and New Zealand: A Retrospective Multicenter Cohort Study. Neurocrit. Care 2018, 29, 443-451. [CrossRef] [PubMed]

26. Russell, D.W.; Janz, D.R.; Emerson, W.L.; May, A.K.; Bernard, G.R.; Zhao, Z.; Koyama, T.; Ware, L.B. Early exposure to hyperoxia and mortality in critically ill patients with severe traumatic injuries. BMC Pulm. Med. 2017, 17, 29. [CrossRef] [PubMed]

27. Branson, R.D.; Johannigman, J.A. Pre-hospital oxygen therapy. Respir. Care 2013, 58, 86-97. [CrossRef] [PubMed]

28. Goldberg, S.A.; Rojanasarntikul, D.; Jagoda, A. The prehospital management of traumatic brain injury. Handb. Clin. Neurol. 2015, $127,367-378$.

29. Thomas, S.H.; Orf, J.; Wedel, S.K.; Conn, A.K. Hyperventilation in traumatic brain injury patients: Inconsistency between consensus guidelines and clinical practice. J. Trauma 2002, 52, 47-52. [CrossRef]

30. Dumont, T.M.; Visioni, A.J.; Rughani, A.I.; Tranmer, B.I.; Crookes, B. Inappropriate prehospital ventilation in severe traumatic brain injury increases in-hospital mortality. J. Neurotrauma 2010, 27, 1233-1241. [CrossRef] 